\title{
DIFFICULT AIRWAY IN A NEONATAL PATIENT WITH GIANT OCCIPITAL ENCEPHALOCELE SETTING SUBJECTED TO SURGICAL CORRECTION
}

Haddad Silveira C., MD; Mateus Marcelino Serzedo P.S., MD; Felloni Tsuha G., MD; Tadeu Bueno Costa C., MD; dos Santos Tarquinio G., MD; Helfenstein E, MD.

\section{Center for Teaching and Training in Anesthesiology (CET-SBA) of the Ribeirão Preto Anesthesiology Clinic (CARP). Ribeirão Preto - SP / Brazil}

\section{BACKGROUND:}

Patients with encephalocele, a rare clinicas condition, makes anesthesia a challenge.

Encephalocele is the neural tube defect characterized by protrusion of the brain and meninges through a defect in the skull.

In addition to the care inherent in pediatric anesthesia, the anesthetist has to deal with the unusual positioning, intubation difficulty and anomalies during the perioperative course.

The use of predictive testing in the assessment of difficult air way, aspartofroutineclinicalpractice, islimitedinprediatricpopulationande speciallyintheneonatalpopulation.

The occurrence of congenital anomalies may indicate the potential for difficult intubation.

\section{CASE REPORT:}

A 12-days-old female neonate,P2 by the ASA classification, $2260 \mathrm{~kg}$, cardiological evaluation class I, with great encephalocele frame in occipital fully associated with microcephaly region, underwent surgery giant posterior encephalocele.

Monitored with SpO2, NIBP, ECG (DII and V5), ETCO2, esophageal temperature and diuresis.

Performed anesthetic induction with fentanyl $(0.7 \mathrm{mcg} / \mathrm{kg})$ and propofol $(2.7 \mathrm{mg} / \mathrm{kg})$.

Endotracheal intubation in the left lateral decubitus with endotracheal tube number 2.5 and maintenance with sevoflurane and nitrous oxide uneventfully.

The manual ventilation under mask was easy and monitoriazaded by capnography.

As rescue devices, had supraglottic device type laryngeal mask, videolaringoscópio Airtraq Neonatal and prompt surgical team to perform cricothyroidotomy puncture or tracheostomy if necessary.

The surgical procedure was uneventful, was referred to neonate ICU hemodynamically stable and intubated, being extubated in the late postoperative period was uneventful.

\section{DISCUSSION:}

The management of children with giant encephalocele requires updated knowledge about the possible difficulties encountered during the perioperative period.

They need specialized anesthesia care to deal with difficult intubation, associated congenital anomalies, unusual positioning, electrolyte disturbances, hypothermia and cardiopulmonary disorders.

The anticipation of possible complicating events, a multidisciplinary comprehensive care during the perioperative period as well as a good relationship with the surgical team are key factors for achieving a safe procedure.

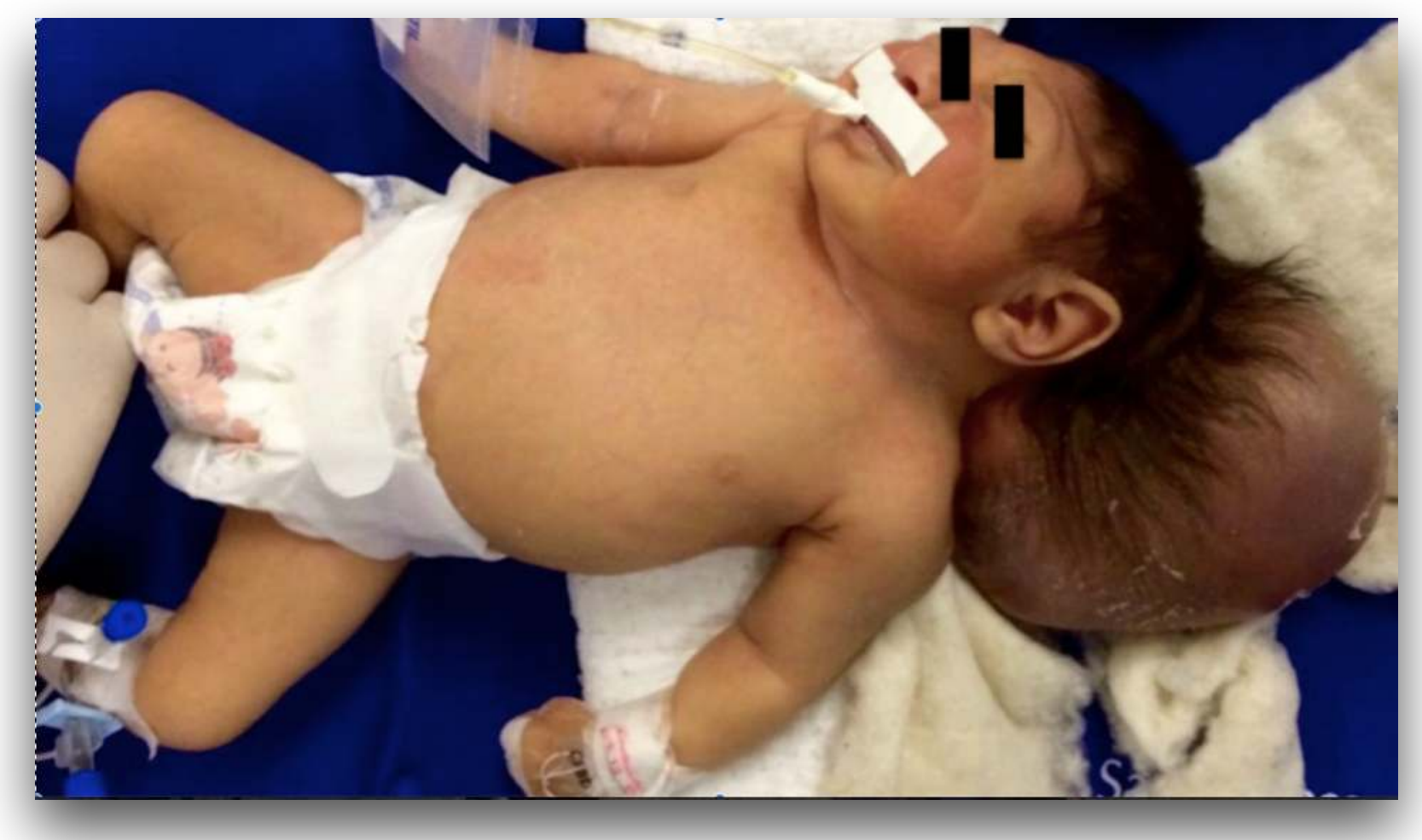

\section{LEARNING POINTS:}

The anesthesiologist must be always alert to identify the syndrome and provide management and treatment in the most accurate and effective manner.

The anticipation of possible complicating events as well as a good relationship with the surgical team are key factors for achieving a safe procedure. 